\title{
O trágico e o riso na arte da travessia
}

\section{Ricardo José Camêlo da Silva}

Mestre em Filosofia pela Faculdade de Filosofia e Ciências Humas da Universidade Federal de Minas Gerais (UFMG) e professor da Faculdade de Educação da Universidade do Estado de Minas Gerais (FaE/UEMG).

rcardocamelo@yahoo.com.br

\section{Resumo}

A natureza do riso é desde sempre um mistério à compreensão do pensamento ocidental. Associado à sabedoria num momento e às ações inferiores noutro, sua história está tramada às diversas manifestações culturais, com importantes implicações éticas e artísticas. Por esse viés estético, ele surge na obra de Nietzsche como notável elemento pedagógico. Em "A gaia ciência” o pensador traça alguns dos elementos pedagógicos contidos no riso, que posteriormente será santificado pelo Zaratustra. O caráter libertário e de leveza nele contidos contrastam com o caráter de peso e aniquilação do trágico. Qual o papel pedagógico do riso? Qual é o sentido do riso? Há nele um aspecto corretivo? Essas são as dúvidas que queremos discutir ao longo do texto.

Palavras-chave: riso; arte; educação; conhecimento. 
Em sua tentativa de exploração e de interpretação do "estar-no-mundo" Carlos Drummond de Andrade, no embalo da "Cantiga de enganar", perscruta - "Há muito aprendi a rir, de quê? de mim? ou de nada?". Drummond nos desperta para possibilidades sérias da vida. "Rir é uma propriedade do homem e dos primatas superiores” (LARAIA, 2007, p. 68). É parte da fisiologia humana, com ricas peculiaridades culturais. Nesse mundo "todos os homens riem, mas o fazem por motivos diversos" (ibid., p.68). Mas qual é o sentido do riso? Há uma função social no risível? Qual é o papel pedagógico do riso?

Ao buscar o significado da comicidade, Bergson constata que ela se dirige à inteligência pura, mas somente a uma inteligência que não vive isolada. “Nosso riso é sempre o riso de um grupo" (BERGSON, 200I, p. 5). Ombreados com o poeta e o filósofo, adentremos nesse universo do risível que traz informações do trabalho humano, da imaginação coletiva, do manifesto popular, de um ethos cultural. Afinal, sendo a comicidade "oriunda da vida real, aparentada com a arte, como não nos diria ela também uma palavra sua acerca da arte e da vida?" (ibid., p. 2).

Parece-nos que a literatura surge com um volume maior e mais vasto quando trata de fazer rir ou mesmo chorar. Recordemos o bobo, companheiro do rei Lear, que com suas intervenções cômicas traz equilíbrio à tragicidade vivida pelo monarca ensandecido. Shakespeare torna emblemático esse personagem, que ri de si também. Na literatura e na sua liberdade, é nesse espaço que o riso tem campo aberto. Ora, também a filosofia se atém a esse exercício que a instiga desde sempre, segundo Bergson (200 I), "impertinente desafio" às especulações. E se a história delega papel importante às reflexões de Aristóteles' sobre esse aspecto, basta reportarmos a algumas décadas e encontramos entre os pré-socráticos essa indagação seminal, particularmente no pensamento de Demócrito. Dos fragmentos do atomista, que indicam, entre outros, pensamentos sobre ética, política e educação, em pelo menos seis o riso e a alegria servem de inspiração às reflexões. Tomemos dois fragmentos: "I 04 - Agradável é o ancião que sabe gracejar e pronunciar palavras sérias. [...] 107aComo homens nos é digno não rir da desgraça dos homens, mas lastimá-la" (BORNHEIM, 1972). ${ }^{2}$

\footnotetext{
' Célebre é o relato sobre uma obra perdida de Aristóteles cujo conteúdo é relativo ao riso e, segundo alguns, seria complementar à Poética.

${ }^{2}$ Os outros são os que se seguem: “ 189 - O melhor para o homem é viver com o máximo de alegria e o mínimo de tristeza. Isto acontece quando não se procura o prazer em coisas perecíveis. [...] 194 - As grandes alegrias provêm da contemplação das belas obras. [...] 200 - Os insensatos vivem sem alegria na vida. [...] $20 \mathrm{I}$ - Os insensatos aspiram a uma longa vida, sem tirar dela nenhuma alegria. [...] 232 - Entre os prazeres, o mais raro traz maior alegria“ (BORNHEIM, 1972).
} 
A nossa questão chega a um novo patamar se fizermos um recuo no tempo para além das propostas aristotélicas ${ }^{3}$. Com o pré-socrático estamos na gênese da filosofia onde os problemas autênticos foram postos e desde então repensados, e repensados uma vez mais. Mas se Demócrito envolve o riso entre os espaços atômicos, Aristóteles o eleva a outro patamar, vestindo-o de um caráter essencialmente humano ao definir "o homem como o único animal capaz de rir - embora na maioria das vezes ele seja definido como o animal que fala e pensa" (JAEGER, 200I, p. 4I6). No entanto, na sua arte "Poética", o papel que o filósofo relega à comédia é de um caráter inferior dentro da hierarquia humana. A comicidade tem pouco mérito nesses valores, remete às ações dos homens inferiores, diversamente da tragédia, que busca imitar as ações dos homens superiores. Com essas caracterizações, Aristóteles abre um vasto horizonte aos seus pósteros.

Como uma gargalhada desmedida, nos transportamos num lapso de tempo e chegamos à idade moderna. "A poética da época moderna baseia-se essencialmente na obra de Aristóteles; sua história é a recepção dessa obra" (SZONDI, 2004). Chegamos ao mundo do Monsieur Descartes. Sob as abas de uma razão renovada, abrindo as portas da era moderna, Descartes define o riso em "As paixões da alma":

o riso consiste em que o sangue que procede da cavidade direita do coração pela veia arteriosa, inflando de súbito e repetidas vezes os pulmões, faz com que o ar neles contido seja obrigado a sair daí com impetuosidade pelo gasnete, onde forma uma voz inarticulada e estrepitosa; e tanto os pulmões, ao se inflarem, quanto este ar, ao sair, impelem todos os músculos do diafragma, do peito e da garganta, mediante o que movem os do rosto que tem com eles qualquer conexão; e não é mais que essa ação do rosto, com essa voz inarticulada e estrepitosa, que chamamos riso (DESCARTES, 1987, p. 121 , art. 124).

Se nesse momento ele apenas descreve sua fisiologia, mais adiante ele nos apresenta sua utilidade e o caráter social nele envolvidos.

Pelo que respeita à troça modesta, que repreende utilmente os vícios, fazendo-os parecer ridículos, sem que entretanto a gente mesmo se ria disso nem testemunhe nenhum ódio contra as pessoas, não é uma paixão, mas uma qualidade de homem de bem, que patenteia a alegria de seu humor e a tranqüilidade de sua alma, as quais constituem marcas de virtude e muitas vezes

\footnotetext{
${ }^{3}$ Essa reflexão de Aristóteles parece estar atrelada ao conceito de "catarse". Segundo Reale: "Aristóteles devia explicar mais profundamente o sentido da catarse no segundo livro da Poética, que infelizmente se perdeu" (REALE, I994).
} 
também a finura de seu espírito, por saber dar uma aparência agradável às coisas de que zomba (ibid., p. 145, art. 180).

Na metade do século XIX, Schopenhauer, o cavaleiro solitário da filosofia, em "Parerga e paralipomena", no capítulo sobre as "contribuições à doutrina da afirmação e da negação do querer viver”, nos brinda com uma passagem emblemática sobre o ato da geração. Diz o misantropo:

poderia parecer também que o demônio quis apenas esconder o seu jogo, pois o coito é suas arras e o mundo seu reino. Já não se disse que illico post coitum cachinnus auditur Diaboli? ? $^{4}$ o que, falando sério, repousa em que o desejo sexual, sobretudo quando, por fixação em uma determinada mulher, se concentra em paixão, constitui a quintessência de todo o logro deste nobre mundo; pois é tão indizível, infinita e exageradamente promissor, e cumpre tão miseravelmente pouco (SCHOPENHAUER, 1985, § I66).

Essa risada do diabo nos aponta caminhos para uma investigação do significado do risível e seu liame ético em suas reflexões. Mas a questão do riso para Schopenhauer esta ligada à incongruência entre os "objetos reais" e os "conceitos" relacionados a esses objetos. $O$ objeto que se deixa pensar pelo conceito é para ele, no entanto, totalmente estranho e em tudo diferente do pensado pelo conceito. Para Schopenhauer, a incongruência que se dá entre os conhecimentos "abstrato" e "concreto" provocaria o riso. Pensado como o elemento mais importante em sua teoria sobre o riso, essa incongruência do pensado (Gedachten) e o contemplado (Angenschauten) leva Alberti a indicar um espaço importante ao conhecimento intuitivo.

A causa desse prazer é a vitória da representação intuitiva sobre a abstrata, do entendimento sobre a razão: percebemos que a razão, com seus conceitos abstratos, não é capaz de descer à infinita diversidade e às nuanças do concreto, isto é, da forma de conhecimento primeira. $O$ concreto é o meio do presente, do regozijo e da alegria, e não implica esforço algum. Além disso, o conhecimento intuitivo não é subordinado ao erro e não tem necessidade de comprovante do exterior; ele se sustenta a si mesmo (ALBERTI, 2002).

Por esse pequeno curso, podemos notar que o riso e seus significados têm lugar de destaque na especulação filosófica. E que o seu caráter universal expressa também uma linguagem particular com "um determinado padrão para este fim" (LARAIA, 2007, p. 69). Avançando um pouco mais, porém ainda sob os auspícios da modernidade, encontramos entre as obras de Nietzsche, leitor, ad-

\footnotetext{
${ }^{4}$ Schopenhauer, Parerga e paralipomena § 166: “Logo após o coito, ouve-se a gargalhada do Diabo" (N.E.)
} 
mirador e posteriormente antípoda de Schopenhauer, o riso como elemento fundamental e condição necessária para educar o "espírito livre”. Sabedores que a obra desse pensador tem o aforismo como expressão, também esse tema não foi tratado de modo sistemático, nos obrigando a recolher passagens aqui e ali e moldar um mosaico lúdico onde o riso se manifesta entremeado pelo "sério" que a filosofia exige. Dentre seus escritos, "A gaia ciência” destaca-se profícua em teses dessa natureza. É lá que o riso (iachen) e seus significados surgem em momentos diversos ao longo de suas páginas. Nela leitores incautos são advertidos logo no intróito. "Vivo em minha própria casa, Jamais imitei algo de alguém $E$ sempre ri de todo mestre Que nunca riu de si também"5 (NIETZSCHE, 200I).

A seriedade que damos aos aspectos racionais da vida, e a aversão em relação ao riso é a advertência do pensador que leva a outros limites, os modos de pensar e questionar a razão. Essa máquina "pesada, escura e rangente" que é o intelecto quando em movimento e com o propósito de bem pensar, Nietzsche diz que implica em seriedade e incômodo e manifesta intolerância.

A graciosa besta humana perde o bom humor, ao que parece, toda vez que pensa bem; ela fica "séria"! E "onde há riso e alegria, o pensamento nada vale"; - assim diz o preconceito dessa besta séria contra toda "gaia ciência". - "Muito bem! Mostremos que é um preconceito!" (NIETZSCHE, 200I, p.217, §327).

Ao longo das suas páginas petulantes, traquinas e em busca da "suprema esperança", o riso vai sendo tramado a outros problemas humanos e seu papel na educação toma outros contornos.

Mas você nunca achará quem possa zombar de você, indivíduo, também no que tem de melhor, fazendo-o perceber, tanto quanto exigiria a verdade, sua ilimitada miséria de rã e de mosca! Rir de si mesmo, como se deveria rir para fazê-lo a partir da verdade inteira - para isso os melhores não tiveram bastante senso de verdade até hoje, e os mais talentosos tiveram pouco gênio! Talvez ainda haja um futuro também para o riso (ibid., p.52, §I).

A obra, que vai em busca do "mar de sua suprema esperança", é também um manifesto à alegria e exalta o riso como elemento pedagógico. As inferências sobre o seu papel de educador atingem um ápice quando suas críticas são voltadas para os homens que dirigem os modelos e projetos educacionais da

\footnotetext{
${ }^{5}$ Ich wohne in meinem eigenem Haus Hab Niemandem nie nichts nachgemacht Und - lachte noch jedem Meister aus, Der nicht sich selber ausgelacht.

${ }^{6}$ Refere-se à epigrafe do Livro IV onde lemos: "Ó tu, que com dardo de flama parte o gelo da minha alma, para que ela se lance fremente ao mar de sua suprema esperança: sempre mais clara e mais sã, livre na lei mais amorosa - assim exalta ela teus milagres belíssimo Janeiro!" (NIETZSCHE, 200I)
} 
Alemanha do século XIX “Contribuição ao 'sistema educacional' - Na Alemanha falta aos homens superiores um grande meio de educação; a risada dos homens superiores; estes não riem na Alemanha" (NIETZSCHE, 200 I, § I 77).

Num aforismo de teor crítico a Spinoza, o riso assume um lugar no processo do conhecimento, mostra sua força nesse exercício cognitivo e reafirma sua existência e condição humana.

Non ridere, non lugere, neque detestari, sed intelligere! (Não rir, não lamentar nem detestar, mas compreender!) Disse Spinoza, da maneira mais simples e sublime que é sua. No entanto, que é intelligere, em última instância, senão a forma na qual justamente aquelas três coisas tornam-se de uma vez sensíveis para nós? Um resultado dos diferentes e contraditórios impulsos de querer zombar, lamentar, maldizer? Antes que seja possível um conhecer, cada um desses impulsos tem de apresentar sua visão unilateral da coisa ou evento; depois vem o combate entre essas unilateralidades, dele surgindo aqui e ali um meio termo, uma tranqüilização, uma justificação para os três lados, uma espécie de justiça e de contrato: pois é devido à justiça e ao contrato que esses três impulsos podem se afirmar na existência e conservar mutuamente a sua razão (NIETZSCHE, 200I, p. 220, §333).

"A gaia ciência" traça de modo vigoroso as novas perspectivas para o riso e prepara o palco para a entrada dos pensamentos mais profundos e originais de Nietzsche, amadurecidos ao longo dos ligeiros aforismos. E antes de iniciar a tragédia (incipit tragoedia) do Zaratustra deixa indicado no cômico a possibilidade de sua solução:

eu mesmo, que fiz inteiramente só essa tragédia das tragédias, até onde ela possa estar pronta; eu, que primeiramente atei o nó da moral na existência, e depois o apertei de forma tal que somente um deus o poderá desatar - como exige Horácio! -, eu próprio matei agora todos os deuses no quarto ato - por moralidade! Que será agora do quinto ato? De onde tirarei a solução trágica? - Devo começar a imaginar uma solução cômica? (NIETZSCHE, 200I, p.162, §I53).

"A gaia ciência" ao anteceder os vaticínios de Zaratustra traz os elementos de sua redenção e do seu conhecimento embrionários entre os aforismos. Através dos ensinamentos do persa Zaratustra, chegamos a um outro patamar da filosofia trágica de Nietzsche, que dá agora um significado positivo ao aspecto trágico. Santificado por Zaratustra, o riso é anunciado como sua grande sabedoria e exercício educador dos homens superiores "Esta coroa do homem ridente, esta coroa de rosas entrelaçadas: eu mesmo a coloquei na mi- 
nha cabeça, eu mesmo santifiquei o meu riso" (NIETZSCHE, 2005, §I8). Assim, anuncia o caráter afirmativo e transformador onde, por meio de seu aprendizado, encontramos a coragem de querer a vida como ela se apresenta, afirmando-a de modo irrestrito. "Ridendo dicere severum [...]" 7 , citando Horácio, Nietzsche principia "O caso Wagner" e parece querer assim, nessa obra de maturidade, viver aquela arte do riso que surge em "A gaia ciência" como potente força artística e pedagógica, posteriormente santificado por Zaratustra.

Queremos defender então as teses de que o riso é para Nietzsche a "catarse" artística por excelência. Exercício pedagógico excepcional. Condição necessária para libertar o espírito do peso da gravidade para a leveza artística. É da coragem do homem. Nessa perspectiva as peças trágicas e as ações dos heróis trágicos fornecem elementos ricos para nossa investigação. Para corroborar essas teses, vejamos.

Édipo quando se reconhece como enigma solucionado, prorrompe entre dores.

Oh! Ai de mim! então no final seria verdade! Ah! Luz do dia, que eu te veja aqui pela última vez, já que hoje me revelo o filho de quem não devia nascer, o esposo de quem não devia ser, o assassino de quem não devia matar! (SÓFOCLES, p. 84).

Também Polinices quando recorre a Édipo para combater Etéocles encontra na resposta de seu pai, o duro significado de sua existência e já emaranhado nas tramas do destino ouve ao longe o canto do bode. E ainda, Ifigênia, que na praia em Áulis, junto às naus gregas, entende toda a tramóia do pai e parte resignada para o sacrifício. Podemos tomar essas passagens como momentos emblemáticos daquilo que os heróis trágicos contemplaram e experimentaram, motivados por suas ações. Aristóteles chamou de reconhecimento ${ }^{8}$ a essa parte da fábula em que o herói compreende seu infortúnio ou sua ventura. Aqui analisadas sob a perspectiva da luta dos dois impulsos, um fomentado por Apolo e o outro por Dioniso, esse momento, que Aristóteles chama de reconhecimento, é atribuído por Nietzsche ao "efeito que o dionisíaco provoca", onde, "[...] toda a sua existência, com toda beleza e comedimento, repousava sobre um encoberto substrato de sofrimento e conhecimento, que lhe era de novo revelado através daquele elemento dionisíaco" (NIETZSCHE, 1992, §4).

Mas é do herói trágico, a dura sanha de viver sob essa lei imperiosa do

\footnotetext{
7 “Rindo, dizer coisas graves..." citação e paródia de Horácio Sátiras I, I, 24 (NIETZSCHE, 1999): [...] ridentem dicere verum quid vetat (o que nos proíbe de, rindo dizer coisas verdadeiras?). Conforme nota do tradutor.

${ }^{8}$ Aristóteles Poética XI - 6I. O reconhecimento, indica-o a própria palavra, é a passagem do desconhecimento ao reconhecimento; tal passagem é feita para a amizade ou ódio dos personagens, destinados à ventura ou ao infortúnio.
} 
destino, e o que resta ao espectador é compadecer dessa sina e vivenciar o alívio através da "catarse" provocada pelas ações heróicas: Édipo ao investigar e se reconhecer, Prometeu aprisionado aos rochedos pelo roubo do fogo divino, ou mesmo Cassandra ao adentrar no palácio de Agamênon e antevendo a fúria de Clitemnestra. Mais do que a "catarse" provocada no espectador, importa aqui esse atributo do dionisíaco de ver o horror.

Somente na medida em que o gênio, no ato da procriação artística, se funde com o artista primordial do mundo, é que ele sabe algo a respeito da perene essência da arte; pois naquele estado assemelha-se, miraculosamente, à estranha imagem do conto de fadas, que é capaz de revirar os olhos e contemplar-se a si mesma; agora ele é ao mesmo tempo sujeito e objeto, ao mesmo tempo poeta, ator e espectador (NIETZSCHE, 1992, § 5).

Esse primeiro momento aponta uma direção ao modus do viver do espírito livre que semelhante àquele artista trágico - ao espectador estético - justifica a existência como fenômeno estético.

Quem não tenha vivenciado isso, ou seja, ter de olhar e ao mesmo tempo ir além do olhar, dificilmente imaginará quão nítidos e claros subsistem, lado a lado, esses dois processos e são, lado a lado, sentidos na consideração do mito trágico: ao passo que os espectadores verdadeiramente estéticos hão de me confirmar que, entre os efeitos peculiares da tragédia, o que há de mais notável é essa co-presença. Basta transferir esse fenômeno, do espectador estético a um processo análogo no artista trágico, e ter-se-á entendido a gênese do mito trágico. Ele compartilha com a esfera da arte apolínea o inteiro prazer na aparência e na visão e simultaneamente nega tal prazer e sente um prazer ainda mais alto no aniquilamento do mundo da aparência visível (NIETZSCHE, I 992 § 24).

Mas é no "Crepúsculo dos ídolos" que Nietzsche dá seu conhecimento definitivo sobre a psicologia da tragédia.

O dizer sim à vida mesma ainda em seus problemas mais estranhos e mais duros; a vontade de vida, tornando-se alegre de sua própria inesgotabilidade em meio ao sacrifício de seus tipos mais elevados - isto chamei de dionisíaco, isto decifrei enquanto a ponte para a psicologia do poeta trágico. Não para se livrar de pavores e compaixões, não para se purificar de um afeto perigoso através de sua descarga veemente - assim o compreendeu Aristóteles -: mas a fim de, para além de pavor e compaixão, ser por si mesmo o eterno prazer do vir a ser - aquele prazer que também encerra em si ainda o prazer na aniquilação [...] (NIETZSCHE, 2000, §5). 
Então rir de si é a redenção e afirmação da vida, o que liberta o espírito trágico para a dança, a sabedoria que transfigura em leveza criadora o espírito de peso, diz o pensador. "Necessitamos de toda arte exuberante, flutuante, dançante, zombeteira, infantil e venturosa” (NIETZSCHE, 200I, § I07) para educação do espírito livre. Acompanhamos aqui os passos de Peter Szondi que, em seu ensaio sobre o trágico, entende que "o dionisíaco irrompe de seu despedaçamento na individuação justamente como um poder indestrutível, que constitui então a 'consolação metafísica' oferecida pela tragédia" (SZONDI, 2004) ${ }^{9}$.

Novamente recorremos a Bergson que agora nos apresenta um aspecto de correção contido no riso, semelhante ao pai da criança que num breve instante se envolve com a travessura do filho, mas no momento seguinte se detém para corrigi-lo.

O riso é, acima de tudo, uma correção. Feito para humilhar, deve dar a impressão penosa à pessoa que lhe serve de alvo. A sociedade vinga-se por meio dele das liberdades tomadas com ela. Ele não atingiria seu objetivo se não trouxesse a marca da simpatia e da bondade (BERGSON, 200I, p. I46).

Mas se é penoso, estará justamente aí seu papel pedagógico? Voltemos aos argumentos do pensador.

Alguém dirá que pelo menos a intenção pode ser boa, que muitas vezes castigamos porque amamos e que o riso, reprimindo manifestações exteriores de certos defeitos, nos convida, para nosso bem, a corrigir esses defeitos e a nos melhorarmos interiormente? (BERGSON, 200 I, p. I46).

A possibilidade do riso no universo humano apresenta nuances e particularidades muito próximas da arte. Os personagens da literatura, por si, já atestam esse fato, desde as peças trágicas e cômicas do teatro grego e as reflexões de Aristóteles sobre essa arte, passando pelos personagens de Shakespeare até as reflexões filosóficas de Nietzsche e o modo de educação transformadora do espírito livre de Zaratustra, bem como a proposta de Bergson e o aspecto corretivo contido no riso. Se ele melhora, corrige, educa, liberta, prepara e redime, é justo ou nos eleva a outro patamar, importa explorarmos esse rico lado humano e as possibilidades que ele nos oferece. E se a educação é um exercício contínuo, o presente já nos pede uma boa risada por estarmos a caminho de sua elaboração.

\footnotetext{
9 Conforme podemos ver em "O nascimento da tragédia": “É uma tradição incontestável que a tragédia grega, em sua mais vetusta configuração, tinha por objeto apenas os sofrimentos de Dioniso, e que por longo tempo o único herói cênico aí existente foi exatamente Dioniso. [...] Que por detrás de todas essas máscaras se esconde uma divindade, eis o único fundamento essencial para a tão amiúde admirada 'idealidade' típica daquelas célebres figuras. Não sei quem asseverou que todos os indivíduos enquanto indivíduos são cômicos e, portanto não trágicos: de onde se deduz que os gregos não podiam suportar em absoluto indivíduos na cena trágica“ (NIETZSCHE, 1992, p.69, §I0).
} 


\section{Referências}

ANDRADE, C. D. de. Antologia poética. Rio de Janeiro: Record, 2007.

ARISTÓTELES. Poética. São Paulo: Nova Cultural, 1987. (Os pensadores)

ALBERTI, V. O riso e o risível na história do pensamento. Rio de Janeiro: Jorge Zahar Ed., 2002.

BERGSON, H. O riso. São Paulo: Martins Fontes, 200 I.

BORNHEIM, G. A. Os filósofos pré-socráticos São Paulo: Cultrix, 1972.

DESCARTES, R. Discurso do método: as paixões da alma. São Paulo: Nova Cultural, 1987. (Os pensadores)

LARAIA, R. de B. Cultura: um conceito antropológico. Rio de Janeiro: Jorge Zahar Ed., 2007.

NIETZSCHE, F. O nascimento da tragédia, ou helenismo e pessimismo. São Paulo: Companhia das Letras, 1992.

. A gaia ciência. São Paulo:Companhia das Letras, 200 I.

. Assim falou Zaratustra: um livro para todos e para ninguém. Rio de Janeiro: Civilização Brasileira, 2005.

. Crepúsculo dos ídolos, ou, como filosofar com o martelo. Rio de Janeiro: Relume Dumará, 2000.

. O caso Wagner: um problema para músicos/ Nietzsche contra Wagner: dossiê de um psicólogo. São Paulo: Companhia das Letras, 1999.

REALE, G. História da Filosofia Antiga. São Paulo: Loyola, 1994. v. 2.

SCHOPENHAUER, A. O mundo como vontade e representação; Crítica da 
filosofia kantiana; Parerga e paralipomena. São Paulo: Abril Cultural, 1985. (Os pensadores)

SÓFOCLES. Édipo rei. Porto Alegre: L\&PM, 1998.

SZONDI, P. Ensaio sobre o trágico. Rio de Janeiro: Jorge Zahar Ed., 2004.

JAEGER, W. Paidéia a formação do homem grego. São Paulo: Martins Fontes, 2001. 


\section{Tragic and the laught in the art of the crossing}

\section{Abstract}

The nature of the laugh is since always a mystery to the understanding of the thought occidental person. Associated to the wisdom at a moment and the inferior actions in another one, its history this conspired to the diverse cultural manifestations, with important ethical and artistic implications. For this aesthetic bias it appears in the workmanship of Nietzsche as notable pedagogical element. In the "Gaia science" the thinker traces some of the contained pedagogical elements in the laugh that later will be become saint for Zaratustra. The libertarian character and of the slightness in it contained contrasts with the character of weight and destruction of the tragic one. Which the pedagogical paper of the laugh? Which is the direction of the laugh? It has in it a corrective aspect? These are the doubts that we want to lead throughout the text to investigate the relation between the laugh and the education.

Keywords: laugh; art; education; knowledge. 